\title{
A trajetória de Chien Shiung Wu e a sua contribuição à Física ${ }^{+*}$
}

\author{
Angevaldo Menezes Maia Filho ${ }^{1}$ \\ Universidade Federal da Bahia e Instituto Federal da Bahia \\ Salvador - BA \\ Indianara Lima Silva ${ }^{1}$ \\ Universidade Estadual de Feira de Santana \\ Feira de Santana - BA \\ Universidade Federal da Bahia \\ Salvador - BA
}

\section{Resumo}

O campo gênero e ciência tem contribuído para a construção de novas histórias, agora, de mulheres cientistas, novos olhares para a prática científica e novas reflexões para uma ciência mais representativa. Com o intuito de contribuir para mais histórias de mulheres nas ciências, discutiremos a trajetória da física experimental sino-estadunidense Chien Shiung Wu e a sua contribuição à física a partir da análise de literatura primária e secundária. Wu é considerada uma das mais importantes cientistas do século $X X$, desenvolvendo técnicas e experimentos que foram extremamente importantes para a física moderna, e, ainda assim, é pouco explorada pela literatura de história das ciências. Ao analisar a sua trajetória, percebemos que Wu enfrentou dificuldades e obstáculos de ordens distintas: segregação hierárquica e institucional, e discriminação de raça e gênero. Por fim, acreditamos que escrever histórias de mulheres cientistas possa contribuir para uma ciência mais representativa, e, consequentemente, para romper com a visão androcêntrica do fazer científico.

Palavras-chave: Chien Shiung Wu; História das Ciências; História das Mulheres; História da Física; Gênero e Ciência.

\footnotetext{
+ The trajectory of Chien Shiung Wu and her contributions to Physics

* Recebido: dezembro de 2018. Aceito: março de 2019.

${ }^{1}$ E-mails: angevaldomaia@gmail.com; isilva@uefs.br
} 


\begin{abstract}
The field gender and science has contributed to the construction of new stories, now, of female scientists, new looks for scientific practices and new reflections for a more representative science. In order to contribute to more stories of women in the sciences, we will discuss the trajectory of Sino-American experimental physics Chien Shiung $W u$ and her contribution to physics from the analysis of primary and secondary literature. Wu is considered one of the most important scientists of the twentieth century, developing techniques and experiments that were extremely important to modern physics, and yet is little explored by the history of science literature. In analyzing her trajectory, we perceive that Wu faced difficulties and obstacles of different orders: hierarchical and institutional segregation, and discrimination of race and gender. Finally, we believe that writing stories of female scientists can contribute to a more representative science, and consequently, to break with the androcentric vision of it.
\end{abstract}

Keywords: Chien Shiung Wu; History of Science; History of Women; History of Physics; Gender and Science.

\title{
I. Introdução
}

O campo gênero e ciência tem contribuído para trazer à tona histórias das mulheres nas ciências e tecnologia, questões de gênero nas práticas científicas e estudos feministas das ciências (FOX KELLER, 1978, 1992, 1995, 2001, 2004; ROSSITER, 1982, 1995, 1997, 2012; SCHIEBINGER, 1989, 1993, 1999, 1997; HARAWAY, 1989; KOHLSTEDT; LONGINO, 1997; HARDING, 1986; KOHLSTEDT, 1995; CITELI, 2000; LOPES, 1998, 2006; LOPES; COSTA, 2005; LIMA; COSTA, 2016). Apesar de os estudos de feministas, historiadoras e filósofas das ciências, ainda no século XXI, há comentários tal como o do exengenheiro, à época, ativo, da Google. "Estou simplesmente afirmando que a distribuição de preferências e habilidades de homens e mulheres difere em parte devido a causas biológicas, e que essas diferenças podem explicar por que não temos uma representação igual de mulheres em tecnologia e liderança", escreveu ele inequivocamente em algo chamado "Manifesto" ".

O conceito de gênero surgiu, justamente, no século passado para enfrentar essa naturalização da diferença sexual. Como bem destacado pela Fox Keller (1995, p. 29), "redefinimos gênero, em contraposição para sexo, para demarcar os significados sociais e políticos, logo variáveis, de masculinidade e feminilidade das categorias biológicas, ou presumivelmen-

2 Disponível em: <https://www.theguardian.com/world/2017/aug/06/google-staffers-manifesto-againstaffirmative-action-sparks-furious-backlash>. Acesso em: 08 agosto 2017. 
te fixas, de homem e mulher". O ex-engenheiro utilizou a definição de sexo, características biológicas, para justificar a baixa representatividade de mulheres nas ciências e em cargos de liderança, externando, assim, um mito construído social, cultural e politicamente. Uma imposição de quais lugares e carreiras são destinados a mulheres e homens na sociedade. Como "um aspecto da organização social em geral", as mulheres "podem ser encontradas em muitos lugares, pois os significados da diferença sexual são invocados e contestados como parte de muitos tipos de lutas pelo poder" (SCOTT, 1999, p. 6). Mais estudos sobre mulheres nas ciências é, sem dúvida, uma forma de contestar e desmistificar a visão de incapacidade das mulheres em fazer ciências e engenharias, bem como, em liderar projetos. Uma forma política de atuar e revelar as diferentes formas de sexismo na academia. Para uma ciência mais plural e diversa, contrariando a visão androcêntrica das ciências, mulheres precisam se sentir representadas nas ciências e tecnologia, e certamente, escrever sobre o seu passado é uma forma de tornar isso uma realidade.

A historiografia tradicional tem negligenciado o legado das mulheres nas ciências e tecnologia (SCHIENBINGER, 1987; KOHLSTEDT; LONGINO, 1997; CITELI, 2000; LOPES, 2008; LOPES; COSTA, 2005; LOPES, 2006; ROSSITER, 1997), contribuindo, assim, para disseminar "a falsa mitologia da[s] ciência[s] como um terreno quase exclusivamente masculino" (ORESKES, 1996, p. 87). Transformar a invisibilidade histórica das mulheres em visibilidade é uma questão de dar-lhes voz e, principalmente, de emancipá-las. De fato, "ficar sem história é estar presa em um presente no qual as relações sociais de opressão parecem naturais e inevitáveis. O conhecimento da história é conhecimento de que as coisas têm mudado e, certamente, mudam" (GREEN; TROUP, 1999, p. 253). Dar visibilidade às mulheres das ciências pode, também, nos ajudar a refletir sobre ações políticas que tornem a ciência um ambiente mais convidativo para as mulheres e, assim, desmistificar a ideia equivocada de que a ciência é apenas, e somente, para homens (KOHLSTEDT, 1995).

$\mathrm{O}$ nosso artigo faz parte do movimento de dar visibilidade às mulheres cientistas através de suas histórias, inserindo-se, assim, na área gênero e ciência dentro da componente história das mulheres nas ciências. Um campo que começou a florescer institucionalmente na transição das décadas de 1970 e 1980 como uma força tarefa contra à historiografia tradicional que excluía deliberadamente a participação das mulheres nas ciências ${ }^{3}$. Conforme Rossiter (1983, p. xv), “o lugar subordinado historicamente às mulheres na ciência (e, assim, a sua invisibilidade para até mesmo historiadores experientes da ciência) não foi uma coincidência e não foi devido a qualquer falta de mérito por parte delas". Com estudos e biografias de historiadoras das ciências e autobiografias de mulheres cientistas, reconfiguramos a área de história das ciências, tornando-a mais representativa a partir de novos olhares, novas narrativas e novas personagens mulheres.

Com o intuito então de contribuir para uma história das mulheres nas ciências e, consequentemente, para uma historiografia representativa e inclusiva, exploraremos a trajetória

\footnotetext{
${ }^{3}$ Para uma revisão sistemática da área, ver Schienbinger (1987) e Fox Keller (1995).
} 
da física experimental sino-estadunidense Chien Shiung Wu a partir da literatura primária e secundária sobre a história das mulheres nas ciências. Wu é considerada uma das mais proeminentes cientistas do século XX na área de física nuclear com estudos sobre o decaimento beta. Foi a primeira pessoa a receber o Prêmio Wolf de Física, e a primeira mulher a presidir a American Physical Society. Wu participou do Projeto Manhattan - um dos maiores projetos científicos do século passado, bem como realizou experimentos que comprovou a violação de uma das teorias mais fundamentais da física - a simetria por paridade.

O seu legado já foi destacado nas biografias de Hammond (2009) e Chiang (2014), e apareceu timidamente em Freire Jr (2014), Kragh (2002) e Jammer (1974). A trajetória de Wu ainda não foi explorada pela literatura nacional de história das ciências, todavia. Hammond (2009) escreveu uma obra de divulgação científica e destacou a contribuição de Wu à física. A sua lacuna foi não ter considerado a relevância do trabalho experimental de Wu para a segunda revolução quântica 4 . Chiang (2014), por sua vez, focou estritamente na sua trajetória de vida, não se preocupando com o seu legado intelectual à física. Nem Hammond (2009) e nem Chiang (2014) exploraram o impacto do experimento de Wu para os fundamentos da mecânica quântica e, muito menos, a literatura sobre mulheres nas ciências nas suas narrativas.

Freire Jr (2014), em seu livro The Quantum Dissidents, realizou um trabalho primoroso no que diz respeito à contribuição de personagens e estudos que não estavam na agenda principal da física quântica na segunda metade do século XX. Ele discutiu o modo pelo qual as pesquisas sobre fundamentos da mecânica quântica passaram para o mainstream da física abrindo o caminho para o que ficaria conhecido como a segunda revolução quântica. A figura de Wu apareceu ligeiramente em Freire Jr (2014) como uma personagem que contribuiu para os primeiros experimentos realizados em laboratório para testar o problema da incompletude da mecânica quântica. No entanto, diante de outros experimentos que sucederam o experimento dela, o legado de Wu não foi explorado plenamente.

Jammer (1974), em Philosophy of Quantum Mechanics, abordou a história e a filosofia da mecânica quântica até a década de 1970. O autor também destacou o experimento de Wu de 1950 quando discutiu a teoria das variáveis ocultas. Novamente, a Wu apareceu timidamente na historiografia tradicional da mecânica quântica, ainda que Jammer (1974, p. 331) tenha mencionado que o experimento de Wu era uma "história interessante". O mesmo aconteceu na obra de Kragh (2002), Quantum Generations, o qual focou em uma história da física do século XX a partir da análise de grandes descobertas. Wu apareceu apenas no tópico de interações fracas, e não há qualquer menção ao experimento de 1950 apesar de ser um livro dedicado à história da física quântica no século XX.

A historiografia tradicional citada anteriormente, não explorou, por exemplo, a questão do sexismo na física, discriminações sofridas pela nossa personagem, dificuldades e obstáculos para conseguir o primeiro emprego e a estabilidade na carreira como mulher cientista.

\footnotetext{
${ }^{4}$ Para mais detalhes, ver Maia Filho e Silva (2019).
} 
A nossa narrativa vai além das biografias da $\mathrm{Wu}$ e da literatura de história da mecânica quântica por trazer à tona a sua trajetória e contribuição à física de modo mais detalhado, e por dialogar com a literatura de história das mulheres nas ciências e com a de história geral. Um novo olhar, uma nova história, para a trajetória da $\mathrm{Wu}$.

$\mathrm{O}$ artigo está estruturado da seguinte forma. Na seção I, apresentaremos um pouco da vida de Chien Shiung Wu na China. A seção II é dedicada à sua chegada aos Estados Unidos. Já, na seção III, discutiremos as suas dificuldades em conseguir o primeiro emprego e a sua participação no Projeto Manhattan. A seção IV aborda, em continuidade, a sua contribuição à física experimental. Na seção $\mathrm{V}$, abordaremos o caso da não premiação da Wu ao Prêmio Nobel de 1957. Por fim, na seção VI, apresentaremos o seu reconhecimento pela comunidade científica a partir da concessão de prêmios e homenagens.

\section{A formação de Wu na China}

O nascimento de Wu foi em 29 de maio de 1912 em um momento transitório do governo chinês que saia da dinastia chinesa e entrava para o regime de República. A cidade natal de $\mathrm{Wu}$, Liuhe, proporcionou-lhe uma infância agradável em comparação com a agitação das grandes cidades na primeira década da República da China. O pai de Wu, Wu Zong-Yi, foi um revolucionário e um entusiasta da cultura chinesa. Zong-Yi lutou na revolta de Xangai em outubro de 1911, contribuindo para a fundação da República da China. Baseado em conceitos de modernidade e feminismo, fundou a Ming De Women's Vocational School, cujo principal objetivo era reduzir o preconceito contra as mulheres por meio da educação. A mãe de Wu também era professora e incentivava os estudos para meninas ${ }^{5}$ (CHIANG, 2014). O seu ambiente familiar foi, assim, um lugar muito favorável e encorajador para a formação de $\mathrm{Wu}$. Isso também foi comum a outras trajetórias de mulheres cientistas, como, por exemplo, Emmy Noether, Maria Goeppert Mayer, Dorothy Hodgkin, Rosalind Franklin, e Irène Joliot-Curie. Todas, inclusive a $\mathrm{Wu}$, nasceram em famílias acadêmicas ou profissionais e acabaram recebendo o seu apoio para seguir uma carreira profissional (MCGRAYNE, 1994).

Aos 11 anos, Wu começou a frequentar o ensino médio na escola voltada para meninas Girl's High School em Soochow, e ingressou em uma turma que formava professores. Wu então teve contato com professores chineses e estrangeiros que ministravam aulas a convite da escola. Foi o caso do professor de filosofia Hu-Shih que ministrou a palestra "Mulher Moderna". Wu já conhecia o seu trabalho e o admirava profundamente. Wu ficou em Soochow até 1929, e após graduar-se com as melhores notas, foi indicada para a National Central University em Nanging (CHIANG, 2014).

$\mathrm{Na}$ universidade, escolheu as ciências como objeto de estudo. O seu entusiasmo pela física, em particular, foi inspirado pelo contato ainda como adolescente com a biografia de

\footnotetext{
5 Infelizmente, não temos mais informações sobre a trajetória da sua mãe. As biografias geralmente focam mais na figura paterna, o que é um caso a ser estudado.
} 
Marie Curie. A trajetória de Curie foi inspiradora para Wu. Segundo os colegas de classe da universidade, Curie era um modelo para $\mathrm{Wu}$ e, sempre que a cientista era mencionada, $\mathrm{Wu}$ externava o seu respeito e admiração (CHIANG, 2014). Isso mostra o quão impactante é a representatividade na escolha da carreira científica pelas mulheres. Essa representatividade é importante para garantir a liberdade de manter diferentes perspectivas e opiniões, sem que ideias sejam rotuladas como "coisa de mulher" (SCHIEBINGER, 2001). Ou, indo mais além, para desmitificar a ideia de que a ciência não é coisa de mulher.

No ano em que ingressou na universidade, 1930, o relacionamento entre a China e o Japão era delicado. A China sofria com diversas humilhações das nações imperialistas e os estudantes da universidade exigiam o seu posicionamento. Inclusive, a reitoria da universidade foi ocupada pelos estudantes em outubro de 1932 com a reivindicação de que a China declarasse guerra contra o Japão, e Wu foi uma das líderes do protesto. Ingressou lá no curso de matemática, mudando um ano depois para a física. O Departamento de Física possuía professores renomados, dentre os quais Shi Shi Yuan, o qual havia trabalhado com Marie Curie na França. Por suas qualidades e seu comprometimento com o curso, após concluir a graduação com honras, Wu foi recomendada a trabalhar no centro de pesquisa Academia Sinica em Taipei, Taiwan, o qual possuía departamentos de pesquisa em física e química (CHIANG, 2014).

Mesmo sem saber quem foi a pessoa que a recomendou, ela aproveitou a oportunidade já que normalmente era necessário realizar exames de admissão para trabalhar lá. A sua supervisora foi a pesquisadora Gu Jing-Wei da área de física com doutorado obtido pela Universidade de Michigan nos EUA. Wu trabalhava com espectroscopia de gases, investigando a estrutura interna dos átomos de gases a baixa temperatura, raios X e cristalografia. Ela passava a maior parte do tempo sozinha no laboratório, já que Gu tinha ainda o compromisso da docência para além da pesquisa no laboratório (ibid.).

$\mathrm{O}$ interesse de $\mathrm{Wu}$ pela física aumentou consideravelmente. Ela decidiu então dar continuidade a sua formação motivada por Gu e Hu-Shi, e acabou sendo aceita pela Universidade de Michigan. Wu já sentia as restrições às quais as mulheres estavam submetidas, mas estava disposta a enfrentá-las. Anos mais tarde, ela relembrou:

\begin{abstract}
A sociedade e as famílias dos EUA, infelizmente, acreditam que a ciência e alguns outros campos são exclusivamente masculino. É diferente na China. Meu pai era um educador, e poderia ter estado à frente de seu tempo. Na década de 1930, a sociedade chinesa percebeu que devíamos implantar todos os recursos - talentos coletivos de homens e mulheres - se quisermos alcançar o Ocidente. O Ocidente está à frente da China em ciência e tecnologia, mas não na utilização efetiva de talentos humanos (WU, 1974).
\end{abstract}

No início do século XX, a China era um antigo império em decadência. A parcela dominante da sociedade vivia do excedente da produção camponesa, e o mercado chinês estava submetido aos interesses de países como Inglaterra, França, Rússia e Japão que possuíam tropas no país. O efeito de tal dominação estrangeira gerava um sentimento ambivalente na 
comunidade intelectual da China. De um lado, a corrente tradicionalista percebia a cultura e o estilo de vida ocidental como o principal motivo da sua decadência. Por outro lado, uma corrente mais atrelada à ideia de modernização atribuía os males do país à resistência da cultura chinesa em incorporar a cultura liberal do ocidente (SADER, 1982).

$\mathrm{O}$ contexto vivenciado por $\mathrm{Wu}$ durante a sua juventude na China favoreceu os seus ideais de igualdade e justiça independente da questão de gênero. Pouco antes do seu nascimento em 1911, iniciava a Revolução Democrática Chinesa que se estendeu até a revolução comunista de 1949. A Revolução tinha como objetivo derrubar o sistema feudal e o regime de latifúndios e foi acompanhada pelo movimento de libertação da mulher. Foi ainda na década de 1930 que o número de mulheres ocupando cargos e profissões importantes aumentou, bem como o número de escolas e faculdades que possuíam uma política de educação mista. Isso levou a um grande número de mulheres que se formavam como professoras, médicas e enfermeiras. A própria National Central University possuía um regime de educação mista (CHING-LING, 1972).

O próprio líder comunista Mao Tse Tung apontava a política latifundiária enquanto principal obstáculo parra eliminar os sistemas de autoridade.

A autoridade política dos latifundiários é a espinha dorsal de todos os outros sistemas de autoridade. Com isso derrubado, a autoridade do clã, a autoridade religiosa e a autoridade do marido, tudo começa a cambalear [...] em uma palavra, todo o sistema e a ideologia patriarcal-feudal está cambaleando com o crescimento do poder dos camponeses (MAO TSE TUNG, 1927 apud CHING-LING, 1972, p. 06).

A percepção de igualdade e justiça era condição necessária para a implementação da República Popular da China, a qual foi proclamada em 1949 concluindo o período da revolução democrática e dando início a revolução socialista. A partir disso, leis foram estabelecidas para garantir a igualdade de direitos entre homens e mulheres. Era possível então encontrar mulheres chinesas ocupando cargos públicos e serviços militares, bem como trabalhando com administração de empresas públicas, comércios e fábricas. As mulheres já estavam, assim, atingindo uma independência econômica (CHING-LING, 1972).

A socialização dos meios de produção e políticas de equidade de gênero, que surgiram tanto na URSS quanto na China, foram fatores imprescindíveis para a ascensão social da mulher. No entanto, a libertação plena da mulher na China não aconteceu com sucesso. A ideologia patriarcal-feudal prevaleceu, principalmente, entre os camponeses e agricultores (SAFFIOT, 2011). O status de liberdade e igualdade atingiu apenas uma parcela das mulheres - as mais favorecidas socialmente, enquanto que a outra parte ainda sentia as marcas do preconceito de gênero (KANNO, 2010).

A perspectiva de uma China com política igualitária entre homens e mulheres foi o que Wu levou para o ocidente quando atravessou o pacífico a bordo do navio President Hoover que aportou na cidade de São Francisco, Califórnia, em 1936. Wu visitou novamente a China depois de duas décadas de sua saída. 


\section{A chegada de Wu aos EUA}

Wu havia escolhido a Universidade de Michigan para dar continuidade aos seus estudos no ocidente. Após conhecer a Universidade de Berkeley, porém, decidiu mudar os seus planos. Berkeley parecia muito mais atrativa e, até mesmo, menos hostil do que Michigan (CHIANG, 2014). À época, a presença de mulheres na maioria das universidades norteamericanas não era apoiada, e, em outras, nem mesmo era permitida em seu quadro. Sabendo que em Michigan havia um centro estudantil que não permitia a entrada de mulheres pelo hall principal, Wu optou por Berkeley em detrimento de Michigan (MCGRAYNE, 1994; CHIANG, 2014). De fato, o Heritage Project, dedicado à história da Universidade de Michigan, mostrou que homens consideravam a presença de mulheres na universidade como uma "experiência perigosa" ${ }^{6}$. Berkeley possuía, ao contrário, mulheres em seu quadro desde os primeiros anos de sua fundação em 1870. Um dos princípios da universidade recém fundada era de admitir mulheres da mesma forma que homens (DOUGLASS, 2007). Outra questão atrativa em Berkeley era o fato de que o Departamento de Física estava se modernizando a passos largos. O então Diretor do Laboratório de Física era Ernest Lawrence que havia ganhado em 1939 o Prêmio Nobel de Física pela sua invenção e desenvolvimento do primeiro cíclotron naquele laboratório (CHIANG, 2014).

Em Berkeley, Lawrence foi o orientador oficial da $\mathrm{Wu}$, mas quem supervisionava de fato o seu trabalho era o italiano Emílio Gino Segrè que havia chegado aos EUA no ano de 1938 e já era um físico renomado (BENCZER-KOLLER, 2009). Ela trabalhou com Segrè estudando os produtos da fissão do urânio utilizando nêutrons produzidos no cíclotron. Durante o doutorado, Wu e Segrè identificaram o Xenônio como um elemento importante na reação em cadeia - essa constatação se tornaria extremamente relevante para o desenvolvimento do Projeto Manhattan. Após a defesa em 1940, Wu ainda permaneceu em Berkeley como assistente de pesquisa (CHIANG, 2014).

Naquele ano, a Segunda Guerra Mundial estava em curso. Havia a preocupação do governo norte-americano em ter potenciais inimigos nos laboratórios de pesquisa, realizando espionagem de modo a obter informações tecnologicamente estratégicas. As universidades foram então orientadas a demitir estrangeiros pagos com recursos estaduais. Lawrence, enquanto gestor do Laboratory Lawrence Berkeley ${ }^{7}$, teve que pensar em estratégias para manter estrangeiros em seu laboratório como Segrè e Wu. Lawrence conseguiu manter Segrè utilizando recursos financeiros da Fundação Rockefeller, e medidas semelhantes foram também adotadas para manter a Wu (HEIBRON; SEIDEL, 1989).

\footnotetext{
${ }^{6} \mathrm{O}$ relato faz parte de um projeto multimídia que se debruça sobre a história da Universidade de Michigan e seus personagens. Disponível em: <https://heritage.umich.edu/stories/the-first-women/>. Acesso em: abr. 2017.

${ }^{7}$ Em 1995, o nome do laboratório mudou para "Ernest Orlando Lawrence Berkeley National Laboratory", conforme informação disponível em: <http://www2.lbl.gov/Science-Articles/Archive/new-name.html>. Acesso em: abr. 2017.
} 
Wu era uma pesquisadora dedicada, e durante o tempo em que permaneceu em Berkeley como uma espécie de estágio de pós-doutorado, adquiriu notoriedade como especialista em fissão nuclear. O próprio Bohr indicava a Wu para palestras sobre o processo de fissão, e Oppenheimer a chamava de "a autoridade" do assunto. Mais tarde, na China, Wu ficou conhecida como a Marie Curie Chinesa (CHIANG, 2014). O fato de conhecer bem os processos da fissão fez com que ela tivesse muita cautela em suas palestras, pois sabia da viabilidade de uma reação em cadeia a partir da fisssão do urânio e do potencial bélico de tais estudos.

Ficou conhecida, inclusive, pelo jornal local Oakland Tribune que dedicou uma reportagem em abril de 1941 aos seus trabalhos:

Uma pequena menina chinesa trabalhou lado a lado com alguns cientistas dos EUA no laboratório de estudos referentes a colisões nucleares. Esta menina é o novo membro da equipe de pesquisa de física de Berkeley. A Sra. Wu, ou mais apropriadamente, a Dra. Wu, aparenta ser mais uma atriz em busca da cultura ocidental. Quieta e tímida na frente de estranhos, mas muito confiante e alerta na presença de físicos e estudantes de pós-graduação (Oakland Tribune, 25 abril de 1941).

O jornal apresentava a Wu como uma jovem chinesa que fazia parte do grupo de pesquisa de Berkeley. O noticiário também chamou a atenção para as suas características físicas, e mostrou a sua foto do passaporte. Wu não parecia uma cientista, mas, sim, "uma atriz em busca da cultura ocidental". Sugere uma ideia de que ser mulher e cientista era algo "inatural", como bem ressaltado por Rossiter (1982, p. xv), "como cientistas elas eram mulheres atípicas; como mulheres elas eram cientistas não usuais". Uma imagem completamente estereotipada das mulheres cientistas. Anos mais tarde, em 1963, em uma entrevista para uma revista de notícias de Nova Iorque, Wu refletiu sobre a imagem difundida das mulheres que faziam ciências:

Na América, há uma imagem errada de que todas as mulheres cientistas são ajudantes, velhas e chatas. É culpa dos homens. Na sociedade chinesa, uma mulher é medida unicamente por seu mérito. Os homens as incentivam a ter sucesso, e elas não precisam mudar as suas características femininas (WU, 1963).

Wu já começava a obter prestígio como pesquisadora. No entanto, mesmo com o reconhecimento por parte de grandes nomes da física, e da própria comunidade externa à ciência, a Universidade de Berkeley se recusava a contratá-la. A maioria dos físicos conseguia empregos para trabalhar em pesquisa voltada à guerra, mas não a Wu. Segrè, por exemplo, dizia que Berkeley estava perdendo uma grande oportunidade por não empregá-la e que a universidade teria conseguido uma "estrela". Àquela época, o diretor do Departamento de Física da Universidade de Berkeley era Raymond Thayer Birge. Em sua autobiografia, Segrè declarou que Birge possuía preconceito contra estrangeiros, especialmente chineses, mulheres e pessoas com sotaque (SEGRÈ, 1993). Wu era chinesa, mulher e tinha dificuldades tanto na pronuncia quanto na escrita da língua inglesa (MCGRAYNE, 1994; CHIANG, 2014). Ela sofreu, portanto, discriminação racial e de gênero. Ao longo da vida acadêmica, Lise Meitner, 
Rita Levi-Montalcini, Marie Curie, Dorothy Hodgkin, e Gerty Cori também sofreram algum tipo de discriminação, seja ela, racial, religiosa, de classe, de gênero e/ou de outra natureza (MCGRAYNE, 1994).

\section{O primeiro emprego e o projeto Manhattan}

No ano de 1940, Wu era doutora em física e reconhecida na academia, mas desempregada. Era incomum contratar mulheres para compor o corpo docente das instituições de nível superior. Nenhuma das vinte maiores universidades dos EUA tinha uma professora em física (MCGRAYNE, 1994). O seu primeiro emprego foi pela Smith College, Massachusetts, uma faculdade particular apenas para mulheres. Fazia parte do grupo de sete faculdades particulares de artes liberais destinadas às mulheres que ficou conhecido como as sete irmãs ${ }^{8}$. Elas recrutavam e mantinham mulheres acadêmicas que não eram contratadas por faculdades tradicionalmente masculinas ${ }^{9}$ (HARWARTH et al.,1997). Schiebinger (2001) destacou que esse era o destino principal de mulheres que se doutoravam em ciências antes da década de 1970, e acrescentou que eram faculdades que não recebiam financiamento do governo para realizar pesquisa e desenvolvimento. Em contrapartida, o MIT, por exemplo, recebia grandes investimentos, mas apenas começou a admitir mulheres na década de 1960.

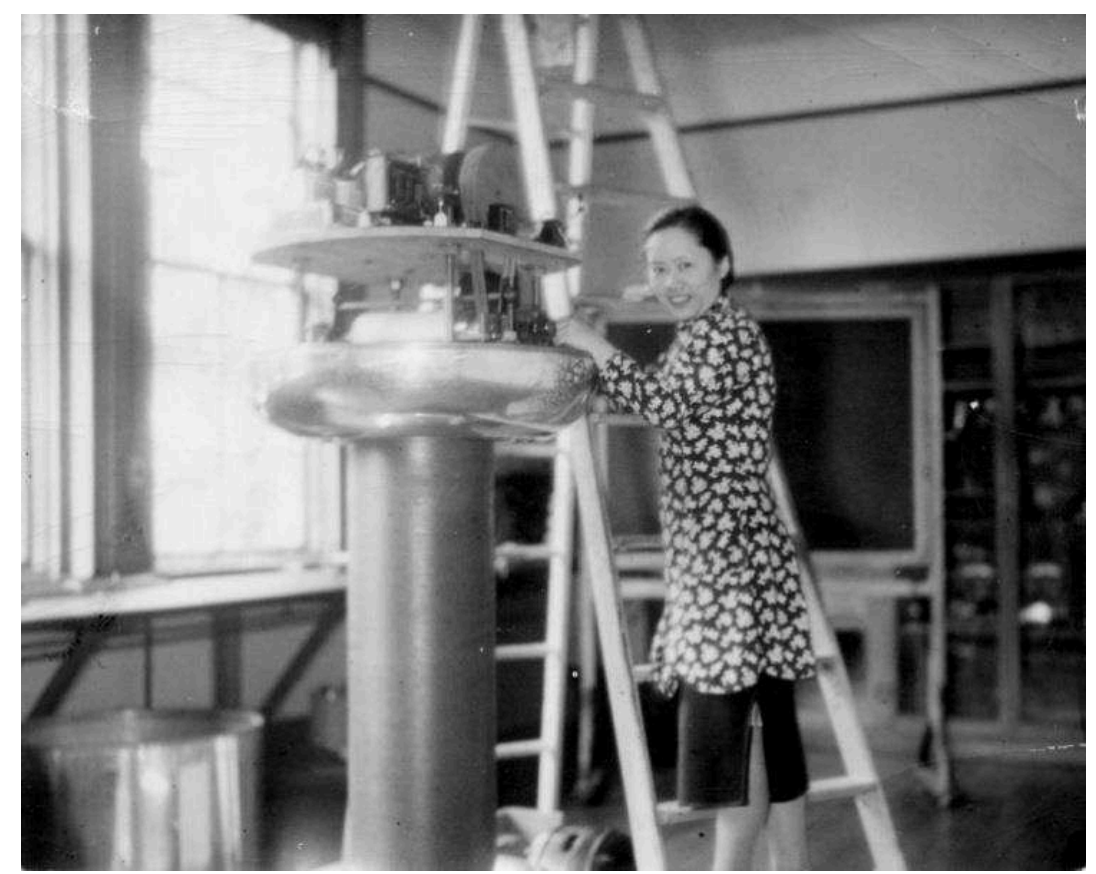

Fig. 1 - Wu montando um gerador eletrostático na Smith College. Fonte: AIP Emilio Segrè Visual Archives.

\footnotetext{
${ }^{8}$ Disponível em: <http://www.smitchcollege.edu>. Acesso em: 20 fev. 2017.

${ }^{9}$ As Sete irmãs eram colleges de Mount Holyoke, Vassar, Smith, Wellesley, Bryn Mawr, Barnard, e Radcliffe. Cinco continuam atualmente sendo faculdades exclusivamente femininas, enquanto que Vassar se tornou uma faculdade mista e Radclife fundiu-se com Harvard. Fonte: <https://www.mtholyoke.edu/about/seven_sisters. html>. Acesso em: 20 fev. 2017
} 
À época, a Smith College não possuía laboratórios de pesquisa, e isso dificultou o andamento das atividades de pesquisa da Wu. Apesar de gostar de dar aulas, a sua grande motivação era a pesquisa em laboratório (MCGRAYNE, 1994). Ao conversar com Lawrence, Wu externou a sua insatisfação e frustração por não estar fazendo pesquisa. Ele, então, decidiu escrever cartas de recomendação para os grandes centros de pesquisa dos EUA. Wu chegou a obter oito ofertas de emprego em Princeton, Brown, Harvard, MIT e Columbia (CHIANG, 2014). Lawrence considerava Wu a física experimental mais habilidosa que ele conhecia e sabia que ela seria de fundamental importância para qualquer laboratório de física (HEIBRON; SEIDEL, 1989).

Wu aceitou a oferta da Universidade de Princeton, tornando-se a primeira mulher instrutora de física da universidade. O local era o mais conveniente para $\mathrm{Wu}$, pois era o lugar no qual o seu marido Luke Chia-Liu Yuan trabalhava. Sobre a sua contratação, em uma palestra, ela relembrou o relato do professor Henry De Wolf Smyth, de Princeton, em 1943, que havia dito para $\mathrm{Wu}$ a dificuldade que teve em empregá-la. Foi a primeira mulher em 211 anos de história da universidade a dar aulas de física (CHIANG, 2014).

No final de 1941, a base militar norte-americana, em Pearl Harbor, foi atacada pelo Japão, levando à entrada dos EUA na Segunda Guerra Mundial. A guerra apontava para a necessidade, cada vez mais urgente, de cientistas trabalhando em laboratórios de pesquisa. Com a guerra em curso, a experiência de uma física experimental como a Wu não podia ser ignorada. Físicos de Berkeley foram convidados para fazer pesquisa de guerra, a exemplo de Robert Oppenheimer, que foi encarregado de desenvolver o projeto da bomba atômica na cidade de Los Alamos no Novo México (MCGRAYNE, 1994). Hammond (2009) destaca que, por ser chinesa, Wu não recebeu nenhum convite de emprego para o trabalho de guerra. Apesar de a China ser um país aliado aos EUA, os estrangeiros eram vistos como potenciais espiões.

Por causa da guerra, Wu permaneceu pouco tempo em Princeton. Meses depois de ter aceitado o emprego, a Divisão de Pesquisa de Guerra da Universidade de Columbia a convidou para uma entrevista. Ela foi interrogada durante um dia inteiro sobre questões de física (MCGRAYNE, 1994). A pesquisadora ainda precisou se submeter a uma espécie de processo seletivo. A intenção era de recrutá-la para o Projeto Manhattan. Apesar de os entrevistadores não revelarem, inicialmente, Wu já sabia do que se tratava ao observar os rascunhos da pesquisa no quadro da sala onde estava acontecendo a entrevista (HAMMOND, 2009; CHIANG, 2014).

Físicos como Enrico Fermi e Leó Szilard, da Universidade de Columbia, receberam financiamento do governo dos EUA para desenvolver pesquisas de enriquecimento de urânio e de reações nucleares em cadeia ${ }^{10}$. Enquanto outros pesquisadores eram convidados a participar do projeto, Wu teve que ser submetida a uma espécie de processo seletivo para demonstrar a sua capacidade intelectual, ainda que nomes como Oppenheimer, Segrè, Glenn Seaborg,

${ }^{10}$ Para mais detalhes, ver <https://www.history.com/topics/world-war-ii/the-manhattan-project>. 
e outros membros do Projeto Manhattan já reconhecerem o seu trabalho. Era requerido um esforço a mais por parte das mulheres que, para exercer as mesmas atividades de um homem, deveriam possuir um "excesso" de habilidades (LÖWY, 2000). Em 1944, a cientista estava nos laboratórios da Universidade de Columbia fazendo trabalho de guerra, enquanto pesquisadora, trabalhando em um projeto que caracterizou a Segunda Guerra como a guerra dos físi$\cos$ (BAGGOTT, 2011).

Apesar de ter o nome de uma única cidade, o projeto de pesquisa iniciado na década de 1940, nos EUA, se instalou em diversos locais do país. Um dos objetivos do projeto era a produção e enriquecimento de urânio. Esse, em seu estado natural, é encontrado na forma de Urânio-238, porém, o elemento que é utilizado na fissão é o Urânio-235. Portanto, era necessária uma separação dos isótopos. Dentre as possibilidades de realização da separação, havia o processo de separação de urânio por centrifugação, separação eletromagnética, difusão gasosa e difusão térmica.

Havia uma forte preocupação de que a Alemanha Nazista construísse um artefato de guerra com tamanha potencialidade de destruição. O Projeto Manhattan reuniu indústrias, empresas e universidades - um projeto ambicioso que buscou os melhores cientistas para desenvolver o mais rápido possível a bomba atômica (HAMMOND, 2009). Wu trabalhou para o Projeto Manhattan, enquanto cientista sênior, vinculada à Universidade de Columbia localizada na cidade de Nova York $^{11}$ (CHIANG, 2014). A sua pesquisa era dedicada ao processo de separação da massa de urânio por difusão gasosa. Wu também aprimorou o contador GeigerMuller, um detector de partículas radioativas, e aumentou a sua sensibilidade (HAMMOND, 2009).

Também foi importante na construção de um reator para estudar as reações em cadeia em Washington (CHIANG, 2014). Problemas surgiram durante a fase de testes do reator. Depois de iniciada, a reação em cadeia não se sustentava, cessava e começava novamente horas depois. Suspeitava-se de que esse fenômeno era causado por conta da absorção de nêutrons por algum elemento resultante da fissão do urânio. O nêutron era o elemento que iniciava o processo de fissão, funcionando, assim, como um gatilho para a reação em cadeia. Dos produtos da fissão do Urânio, o elemento Xenônio era o suspeito de absorver os nêutrons. Na tentativa de solucionar o problema, Fermi entrou em contato com a Wu que havia estudado o Xenônio na sua tese de doutorado (HOWES; HERZENBERG, 2003). À época, por conta do potencial energético associado à fissão nuclear, Wu e Segrè (1945) não haviam publicado integralmente os resultados de suas pesquisas que tratava justamente do Xenônio produzido como produto da fissão do urânio. Fermi e John Archibald Wheeler enviaram então um telegrama para Nova York solicitando os seus resultados preliminares de Wu e Segrè. Ela apenas concordou em fornecer os dados com a condição de manutenção de sigilo. O documento for-

\footnotetext{
${ }^{11}$ Em uma pequena biografia de Wu no site do Centro de Pesquisa Nuclear de Berkeley, ela é apresentada como a única chinesa que participou do projeto Manhattan. Disponível em: <http://physics.berkeley.edu/newsevents/news/20170905/celebrating-women-in-stem-dr-chien-shiung-wu>. Acesso em: 20 abr. 2017.
} 
necido pela $\mathrm{Wu}$ foi uma contribuição significativa para o andamento do Projeto Manhattan. Atualmente, os reatores nucleares utilizam um invólucro de zircônio nas varetas de urânio para evitar o vazamento de xenônio e controlar as reações em cadeia (CHIANG, 2014).

\section{Uma carreira em física experimental}

Após a guerra, Wu permaneceu em Columbia como cientista sênior. Não era uma posição permanente, mas era um cargo de pesquisa com regras que variavam de acordo com a universidade e o salário dependia de fontes externas (HAMMOND, 2009). Wu é geralmente apresentada como uma física experimental à procura de um problema relevante o suficiente para se debruçar e acabou se dedicando a problemas fundamentais da física (MCGRAYNE, 1994; HAMMOND, 2009; BENCZER-KOLLER, 2009).

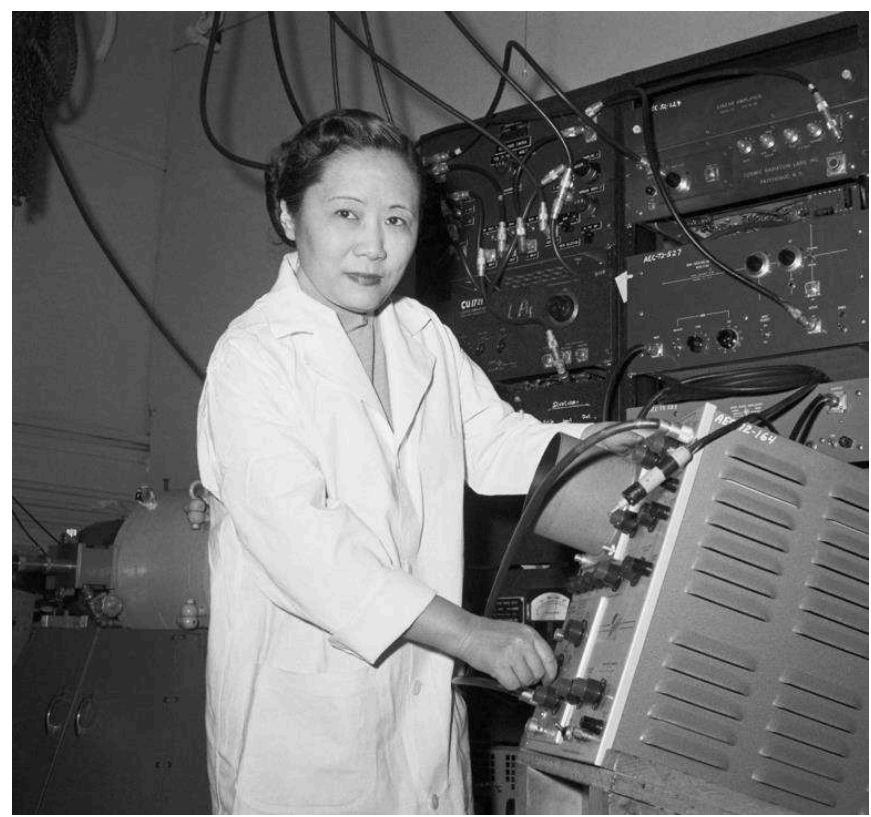

Fig. 2 - Wu no laboratório da Universidade de Columbia em 1958. Fonte: www.history.com ${ }^{12}$.

Em 1934, Fermi havia proposto um modelo teórico para o espectro energético da radiação beta a partir do qual seria possível verificar a energia de cada elétron emitido. Por muitos anos, físicos experimentais tentaram validar ou refutar a teoria de Fermi, pois os resultados experimentais obtidos apresentavam valores de energia muito mais baixo do que o previsto teoricamente (CARUSO; MARQUES, 2014; HAMMOND, 2009). Esse problema ficou relativamente esquecido durante o período da Segunda Guerra quando os esforços dos físicos e os investimentos financeiros estavam voltados completamente para a tecnologia de desenvolvi-

${ }^{12}$ Disponível em: <http://cdn.history.com/sites/2/2014/01/BE055194.jpg>. Acesso em: 13 nov. 2017. 
mento da bomba atômica. No final de 1948, após mais de uma década desde a proposta teórica de Fermi, Wu realizou um experimento que, finalmente, verificou aquela teoria com os dados experimentais (WU; ALBERT, 1949). Esse estudo garantiu-lhe grande respeito e admiração por seus pares. Acreditava-se que a Wu deveria ser indicada ao Nobel pela solução precisa e elegante dada ao problema do decaimento beta (HAMMOND, 2009; MCGRAYNE, 1994). Pelo regulamento, entretanto, o Prêmio Nobel em ciências é oferecido apenas a cientistas que tenham realizado uma descoberta. Como o trabalho de Wu estava relacionado com um aprimoramento de uma técnica, ela não poderia ser laureada com o Nobel. Contudo, de acordo com a crítica de Friedman (2001), "os prêmios Nobel da década de 1940 não foram concedidos com base no reconhecimento do mérito; ao invés disso, tornaram-se, em grande medida, instrumentos na política da ciência”.

Outro experimento realizado por Wu na década de 1950 foi muito relevante para os fundamentos da teoria quântica dando origem ao fenômeno de entrelaçamento quântico (Maia Filho; Silva, 2019). O trabalho de Wu também foi revisitado por David Bohm que o apresentou como a primeira prova experimental para a experiência de pensamento do EPR (BOHM; AHARONOV, 1957). Duarte (2012) enfatizou que a teoria quântica das medidas de polarização dos quanta correlacionados foi proposto em 1947 e confirmado pelo experimento da $\mathrm{Wu}$.

Os experimentos de $\mathrm{Wu}$ já apontavam uma notoriedade, contudo, ela ainda não possuía um emprego efetivo como docente. Mesmo assim, o seu reconhecimento demorou a chegar na Universidade de Columbia (BENCZER-KOLLER, 2009). Apesar de sua recomendação a um cargo de ensino por seus colegas, a Universidade ainda era muito resistente em contratá-la para um cargo efetivo. Um dos homens mais influentes do Departamento de Física de Columbia era Isidor Rabi que possuía uma opinião bastante conservadora em relação às mulheres nas ciências. Hans Jakob Steinberger, que já era professor em Columbia por 18 anos, havia recomendado Wu a um cargo de docente, mas Rabi foi bastante incisivo informando que o cargo de pesquisadora já era suficiente (CHIANG, 2014).

Essa opinião, contudo, não era unânime em relação à contratação de Wu pelo Departamento de Física. O seu colega e amigo Willis Lamb também indiciou em 1951 o seu nome para um cargo na universidade. A recomendação, novamente, foi recusada. Físicos premiados com o Prêmio Nobel que também trabalhavam em Columbia, tais como, Steinberger, Charles Hard Townes, Leon Max Lederman e Tsung Dao Lee, mencionaram que Wu era injustiçada e era discriminada não só pelo fato de ser asiática, mas, também, e mais ainda, por ser mulher (CHIANG, 2014).

No ano de 1952, Wu finalmente se tornou professora associada da Columbia, apenas depois de uma consulta a um comitê externo de cientistas influentes. A sua trajetória foi marcada pela segregação institucional à medida que demorou oito anos para conseguir um cargo permanente, mesmo sendo recomendada por grandes físicos, um fenômeno que não acontece com homens cientistas. Mulheres demoravam muito mais tempo para assumir cargos permanentes do que homens nas mesmas condições, e "elas raramente [eram] convidadas a integrar 
o corpo docente nas universidades de elite" (SCHIEBINGER, 2001, p. 80). A física teórica Maria Goeppert Mayer, Nobel de 1963, por exemplo, passou um longo período realizando trabalho voluntário na universidade. A bioquímica Gerty Cori, por sua vez, apenas conseguiu um cargo como professora quando ganhou o Prêmio Nobel de 1947 (MCGRAYNE, 1994). Outro reflexo da desvalorização da Wu pelo ambiente institucional era ter um salário menor do que o de seus colegas de departamento. No final da década de 1950, após lançamento do Sputnik, os EUA criaram leis de modo a garantir a igualdade de emprego e remuneração entre homens e mulheres (SCHIEBINGER, 2008). Apesar disso, foi apenas em 1975 que Wu teve o seu salário aumentado quando Robert Serber assumiu a presidência da universidade (CHIANG, 2007; 2014).

Seu primeiro e único filho, Yuan Wei-Cheng Vincent, nasceu em 15 fevereiro de 1947 em Princeton. Mesmo com a maternidade, Wu conseguiu continuar as suas atividades de pesquisa. A sua estratégia foi morar a dois quarteirões do laboratório e ter uma empregada para cuidar do filho - dois fatores que ela considerou imprescindíveis para conciliar a maternidade e a carreira científica (MCGRAYNE, 1994). Wu passava o dia inteiro no laboratório em Columbia, enquanto que o seu companheiro Luke trabalhava no Brookhaven National Laboratory em Long Island. Ele viajava na segunda e retornava às sextas para passar o final de semana com a família (MCGRAYNE, 1994). O compromisso da família, a divisão de tarefas domésticas e a existência de creches foram fundamentais para reduzir os conflitos entre a família e a pesquisa. Sobre isso, Wu (1972 apud CHIANG, 2014, p. 180) declarou que "os maridos que realmente respeitam os interesses de suas esposas devem ser atenciosos e dispostos a reduzir o peso que elas carregam". A chegada do filho não impactou na produção acadêmica de Wu que no período entre 1945 e 1950 chegou a publicar vinte e dois artigos. Mas, isso não é o mais comum na vida de mulheres cientistas. A maternidade, muitas vezes, acaba retirando as mulheres do mercado de trabalho de maneira sistemática (COSTA, 2006). De modo implícito, as relações sociais afastam as mulheres das ciências por exigir um comprometimento com o papel de "ser mãe" atribuído ao feminino.

Wu contribuiu ainda com a melhoria de técnicas para medir tempos de vida de átomos muitos pequenos em estados excitados até valores da ordem de $10^{-12} \mathrm{~s}$. Trabalhou, também, com o efeito Mossbauer, em física nuclear, para estudar a estrutura da hemoglobina buscando compreender o seu grau de afinidade com o oxigênio, estimulando, assim, novas pesquisas sobre anemia falciforme. (HAMMOND, 2009, CHIANG, 2014). Ademais, Wu liderou uma equipe de cientistas que trabalhou também com anemia falciforme em colaboração com médicos do St. Luke's Hospital (CHIANG, 2014).

\section{O Nobel de 1957}

A possibilidade de verificação de novas partículas, através do desenvolvimento de aceleradores, levou a uma quantidade incrível de partículas ainda desconhecidas. A partícula theta e partícula tau com características intrigantes, por exemplo, tornaram-se um enigma 
para a comunidade científica. Havia a suspeita de que elas eram a mesma partícula por possuírem massa e tempo de vida iguais. $O$ único fator diferente entre elas era o modo de decaimento. À época, tal mistério ficou conhecido como quebra cabeça ou puzzle theta-tau. O maior problema não era necessariamente o fato de que partículas aparentemente iguais decaíam em modos diferentes, mas, sim, a questão de que, se fossem a mesma partícula, isso violaria uma das propriedades mais fundamentais da física - a conservação da simetria por paridade.

No ano de 1956, dois físicos teóricos, Tsung Dao-Lee e Chen Ning Yang, realizaram um estudo mais cuidadoso da propriedade associada à conservação de paridade das partículas theta e tau. As conclusões que estavam no ar a respeito do assunto: $i$. Os experimentos realizados com a interação fraca não evidenciavam qualquer conservação da paridade; $i i$. As experiências realizadas nas interações eletromagnéticas e nuclear forte corroboravam a conservação da paridade com alto grau de precisão. Não eram capazes, entretanto, de apresentar efeitos de uma não conservação da paridade nas interações fracas (YANG, 1964). Portanto, não havia nenhum experimento capaz de verificar a conservação da paridade em interações fracas. $\mathrm{O}$ problema foi apresentado na Conferência Internacional sobre Física Teórica em Seattle:

Uma vez que partículas têm diferentes valores de rotação e paridade, e têm fortes interações com os núcleos e píons, não se espera que tenham massas e vidas idênticas. A questão permanece em aberto, [e] a indicação de que o $t+e w$ são a mesma partícula não é conclusiva (YANG, 1964, p. 398).

Até então, como o próprio Yang havia comentado, ninguém acreditava que a paridade não era conservada, nem mesmo Lee e Yang. A ideia de um experimento para verificar a violação de uma simetria era encarada como algo inalcançável - uma tentativa que não merecia tanto esforço (MYNENI, 1984). A realização de um experimento dessa natureza exigia equipamentos específicos, bastante habilidade experimental e muitos meses de preparação. Por isso, ninguém aceitou o desafio (MCGRAYNE, 1994).

Mesmo considerando que a possibilidade de a paridade ser violada era de uma em um milhão, Wu acreditava que, exatamente por ser tão básica e fundamental, era importante corroborar ou refutar uma lei física (MCGRAYNE, 1994). Em uma conversa com Lee, Wu perguntou se havia alguma proposta experimental para verificar a paridade em interações fracas, e ele respondeu que físicos haviam indicado essa possibilidade através de um reator. Todavia, Wu utilizou fontes de radiação beta de amostras de Co60 (HAMMOND, 2009).

Grandes nomes da física, como Wolfgang Pauli, não acreditavam que era possível uma violação da paridade. Pauli, amigo de Wu, em uma carta endereçada a Victor Weisskopf, escreveu que estava disposto a apostar uma grande quantia de dinheiro no fato de que a paridade seria conservada (YANG, 2005). Considerando o experimento leviano, Richard Feynman apostou com Norman Ramsey, chances de 10.000 a 1, que o experimento seria um insucesso (CHIANG, 2014).

A realização do experimento exigia técnicas que Wu não tinha disponível nos laboratórios da Universidade de Columbia. Para não destruir o alinhamento dos átomos de Cobalto 
60 era preciso temperaturas incrivelmente baixas da ordem de $10^{-2} \mathrm{~K}$. Poucos laboratórios dos EUA possuíam essa tecnologia. Wu entrou então em contato com Ernest Ambler, recentemente vindo de Oxford para os Laboratórios de Baixa Temperatura em Washington, e ele aceitou com entusiasmo a proposta de colaboração para a realização do experimento (HAMMOND, 2009).

$\mathrm{O}$ trabalho de $\mathrm{Wu}$ revolucionou a física. O resultado de que a simetria por paridade havia sido violada foi impactante na comunidade científica (WU et al., 1957). Em 1957, os teóricos que propuseram o experimento foram laureados com o Nobel de Física. Wu não foi incluída na premiação. Físicos acreditavam que ela deveria ter sido premiada, tal como Steinberger, Nobel em 1988, o qual externou que o maior erro cometido pelo Nobel foi não ter premiado a $\mathrm{Wu}$ (CHIANG, 2014).

Oppenheimer, enquanto diretor dos estudos avançados de Princeton realizou um banquete de celebração convidando $\mathrm{Wu}$, Lee e Yang. Em um breve discurso, ele informou que ali havia três pessoas merecedoras do prêmio (CHIANG, 2014). O Prêmio Nobel é oferecido para cientistas que realizam novas descobertas (HAMMOND, 2009). Wu tinha, agora, realizado a descoberta de que a paridade não é conservada no decaimento beta. Ainda assim, não foi reconhecida com o Nobel.

Chiang (2014) apontou que uma razão para a não premiação de Wu está relacionada à sua rede de colaboradores, a saber, Ernest Ambler, Raymond Hayward, Ralph Hudson e Dale Hoppes. Conforme o autor, eles se sentiriam como "meros técnicos" enquanto Wu apareceria como a personagem que mais se destacou no experimento. Essa insatisfação teria motivado o comitê a evitar uma injustiça, laureando Wu e não os seus colaboradores.

Essa não é a melhor explicação para o caso do Nobel de 1957, mas, sim, a segregação hierárquica. O número de mulheres cientistas ocupando cargos de poder ou recebendo as premiações consideradas as mais renomadas vai diminuindo exponencialmente comparado com o de homens (ROSSITER, 1982). O Prêmio Nobel é reconhecido como uma das mais importantes premiações científicas, garantindo aos laureados ainda mais poder e prestígio na comunidade, e é um reflexo da segregação hierárquica pela sub-representação das mulheres nas áreas científicas e tecnológicas. O Nobel não reflete, portanto, a diversidade da comunidade científica em termos de raça, gênero, classe e etnia.

Wu sofreu a segregação hierárquica, mesmo sendo indicada sete vezes ao Nobel pela sua contribuição à física. Em 1958 recebeu indicações de Willis Eugene Lamb Jr e Polykarp Kush; em 1959 de J. Rossel; em 1960 de David Henry Frisch; em 1964 de Herwig Schopper; e, em 1965 de Emílio Segrè. O caso de Wu não está isolado quanto à questão do Nobel e à segregação hierárquica. A Tabela 1 mostra outras mulheres cientistas que foram indicadas a ganhar o Nobel em Física, e que também sofreram a segregação hierárquica e/ou discriminação de outra ordem. 


\begin{tabular}{|l|c|}
\hline \multicolumn{1}{|c|}{ Cientista } & Indicações - Física \\
\hline Dorothy Crowfoot Hodgkin (1910-1994) & 8 \\
\hline Hertha Wambacher (1903-1950) & 1 \\
\hline Irène Joliot-Curie (1897-1956) & 15 \\
\hline Lise Meitner (1878-1968) & 29 \\
\hline Margaret Burbidge (1919-) & 1 \\
\hline Marietta Blau (1894-1970) & 4 \\
\hline Total & 58 \\
\hline
\end{tabular}

Fonte: https://www.nobelprize.org/.

De um total de 204 prêmios entregues para cientistas até os dias atuais, apenas três mulheres foram laureadas, a saber, Marie Curie em 1903 (indicada três vezes), Maria Goeppert Mayer em 1963 (indicada vinte e seis vezes), e recentemente, 2018, Donna Strickland. Esses dados indicam que um pouco mais de um por cento $(1,47 \%)$ de mulheres foram premiadas com o Nobel em Física desde quando a premiação foi criada em 1901. Utilizar o Nobel como o indicador de quem produz ciências e tecnologia pode acabar desconsiderando o papel das mulheres no desenvolvimento científico e tecnológico, bem como o de outras minorias.

\section{Reconhecimentos e premiações}

Wu recebeu diversos títulos e premiações ao longo da sua trajetória como cientista. Foi a primeira mulher a ensinar em 1943 na e a receber o título de Honorary Doctor pela Universidade de Princeton. Também foi a primeira mulher a fazer parte em 1952 do Departamento de Física da Columbia. Foi eleita, em 1958, para a Academia de Ciências dos Estados Unidos. Wu foi em 1975 a primeira mulher presidenta American Physics Society (APS). Foi agraciada com a medalha Nacional de Ciência pelo presidente dos Estados Unidos Gerald Ford. Também foi condecorada com o Prêmio Wolf, uma das premiações mais importante após o Nobel, sendo a primeira cientista e, consequentemente, a primeira mulher contemplada pelas suas contribuições com o decaimento beta.

The Purple Mountain Observatory, localizado na capital chinesa, chamou em 1990 o asteroide $\mathrm{n}^{\circ} 2752$ de C. S. Wu's Star pelas suas contribuições científicas. Ainda recebeu o título Honorary Doctor de mais de vinte universidades como uma forma de reconhecimento pelas suas contribuições à física (LU, 2012). A Universidade Southeast na China construiu um memorial em sua homenagem com parte de seus pertences e manuscritos doados pela Universidade de Columbia. 
Wu se aposentou em 1981, mas não se afastou das atividades acadêmicas. Passou a dar mais palestras sobre física e a refletir sobre a pouca participação das mulheres nas ciências. Faleceu em 1997 em Nova York, com 86 anos, após sofrer um derrame cerebral (MCGRAYNE, 1994).

\section{Considerações finais}

A trajetória de $\mathrm{Wu}$ possibilitou refletir sobre os obstáculos com os quais ela teve que se deparar ao longo da sua carreira como mulher cientista: segregação hierárquica e institucional, discriminação racial e de gênero.

Ela enfrentou dificuldades por ser estrangeira em um país como os EUA, no seu primeiro emprego que não lhe permitiu avançar na pesquisa experimental, no atraso para conseguir um cargo efetivo como professora, e, por fim, o seu valor à ciência não foi reconhecido pela premiação do Nobel.

Apesar de todas as dificuldades e obstáculos, Wu foi, é considerada, uma das mais importantes cientistas na área de física experimental do século XX e, mesmo assim, a sua história ainda é pouco conhecida.

\section{Agradecimentos}

Gostaríamos de agradecer as/os pareceristas anônimas/os pelos comentários e sugestões enriquecedoras.

\section{Referências}

BAggotT, J. The First War of Physics: The Secret History of the Atom Bomb, 19391949. Pegasus Books, 2011. 584 p.

BENCZER-KOLLER,N.Chien-Shiung Wu (1912-1997), Biographical Memoirs. Washington, National Academy of Sciences, 2009.

BOHM, D.; AHARONOV, Y. Further discussion of possible experimental tests for the paradox of Einstein, Podolsky and Rosen. Il Nuovo Cimento (1955-1965), v. 17, n. 6, p. 964-976, 1960.

CARUSO, F.; MARQUES, A. J. Sobre a viagem de Enrico Fermi ao Brasil em 1934. Estudos avançados da Universidade de São Paulo, v. 28, n. 82, p. 279-289, 2014.

CHIANG, T.C. Wu Chien-Shiung: A brief biography. AIP Conference Proceedings. AIP Publishing, 2015.

CHIANG, T.C. Madame Chien-Shiung Wu: The First Lady of Physics Research. Tradução: Frank Wong Tang-Fong. World Scientific, 2014. 
CHING-LING, S. Women's Liberation in China. Peking Review, Pequim n. 6, p. 6-7, 1972.

CITELI, M. T. et al. Mulheres nas ciências: mapeando campos de estudo. Cadernos Pagu, n. $15,2000$.

COSTA, M. C. Ainda somos poucas: exclusão e invisibilidade na ciência. Cadernos Pagu, n. 27, p. 455-459, 2006.

DOUGLASS, J. A. The conditions for admission: Access, equity, and the social contract of public universities. Stanford University Press, 2007. 352 p.

DUARTE, F. J. The origin of quantum entanglement experiments based on polarization measurements. The European Physical Journal H, p. 1-8, 2012.

FOX KELLER, E. Reflections on Gender and Science. New Haven: Yale University Press, 1995.

Secrets of Life, Secrets of Death. New York: Routledge Press, 1992.

.What Impact, if any, has feminism had on science? J. Bioscience, v. 29, n.

$1,2004$.

Gender and science. Psychoanalysis and Contemporary Thought, v. 1, n.

3, p. 409-433, 1978.

FREIRE JR, O. The Quantum Dissidents: Rebuilding the Foundations of Quantum Mechanics (1950-1990). Springer, 2014.

FRIEDMAN, R. M. The Politics of Excellence. Behind the Nobel Prize in Science. New York: Times Books, 2001.

GREEN, A.; TROUP, K. (Ed.). The houses of history: A critical reader in twentiethcentury history and theory. Manchester University Press, 1999.

HAMMOND, R. Chien-Shiung Wu: Pioneering Nuclear Physicist. New York: Chelsea House Publishers, 2009. 124 p.

HARAWAY, D. J. Primate visions: Gender, race, and nature in the world of modern science. New York: Routledge Press, 1989.

HARDING, S. G. The science question in feminism. Cornell University Press, 1986.

HARWARTH, I.; DEBRA, E.; MALINE, M. Women's colleges in the united states: History, Issues, \& Challenges. DIANE Publishing, 1997. 122 p. 
HEILBRON, J. L.; SEIDEL, R.W. Lawrence and his laboratory: A History of the Lawrence Berkeley Laboratory. University of California Press, 1989. 586 p.

HOWES, R. H.; HERZENBERG, C. L. Their day in the sun: women of the Manhattan Project. TempleUniversity Press, 2003. 264 p.

JAMMER, M. Philosophy of Quantum Mechanics: the interpretations of quantum mechanics in historical perspective. 1974.

KANNO, J. S. M. "As Boas Mulheres da China": uma análise historiográfica a respeito da representação da mulher chinesa na obra de Xinran (1980-1997). In: SEMINÁRIO INTERNACIONAL FAZENDO GÊNERO 9: DIÁSPORAS, DIVERSIDADES, DESLOCAMENTOS, 2010, Florianópolis, UFSC.

KOHLSTEDT, S. G. Women in the history of science: An ambiguous place. Osiris, v. 10, p. 39-58, 1995.

KOHLSTEDT, S. G.; LONGINO, H. The women, gender, and science question: What do research on women in science and research on gender and science have to do with each other? Osiris, v. 12, p. 3-15, 1997.

KRAGH, H. Quantum generations: A history of physics in the twentieth century. Princeton University Press, 2002. p. 216-217.

LEVI-MONTALCINI, R. Reflections on a Scientific Adventure. In: RICHTER, D. (Org.). Women Scientist: The Road to Liberation, Macmillan, New York, 1982. cap. 7, p. 99-117

LIMA, B. S.; COSTA, M. C. Gênero, ciências e tecnologias: caminhos percorridos e novos desafios. Cadernos Pagu, n. 48, 2016.

LOPES, M. M. et al. Sobre convenções em torno de argumentos de autoridade. Cadernos Pagu, v. 27, 2006.

LOPES, M. M.; COSTA, M. C. Problematizando ausências: mulheres, gênero e indicadores na História das Ciências. Gênero nas fronteiras do sul, 2005.

LÖWY, I. Universalidade da ciência e conhecimentos "situados". Cadernos Pagu, n. 15, p. 15-38, 2000.

LU, T. Scientific Achievements of Prof. ChienShiung Wu. Asia Pacific Physics Newsletter, v. 1, n. 02, p. 52-59, 2012.

MAIA FILHO, A. M.; SILVA, I. The WS experiment of 1950 and its implications for the second revolution of quantum mechanics. Revista Brasileira de Ensino de Física, v. 41, n. 2, 2019. 
MCGRAYNE, S. B. Mulheres que ganharam o Prêmio Nobel em Ciências. Marco Zero, 1994. $410 \mathrm{p}$.

MYNENI, K. Symmetry destroyed: The failure of Parity. History of Science: Parity Violation. December, v. 10, 1984.

ORESKES, N. Objectivity or heroism? On the invisibility of women in science. Osiris, v. 11, p. 87-113, 1996.

PERES, A.; SINGER, P. On possible experimental tests for the paradox of Einstein, Podolsky and Rosen. Il Nuovo Cimento (1955-1965), v. 15, n. 6, p. 907-915, 1960.

ROSSITER, M. W. Which Science? Which women? Osiris 12, v. 1, 1997.

Women Scientists in America: Before Affirmative Action, 1940-1972.

Baltimore: Johns Hopkins University Press, 1995.

Women Scientists in America: Forging a New World Since 1972.

Baltimore: Johns Hopkins University Press, 2012.

Women scientists in America: Struggles and strategies to 1940. Baltimore: Johns Hopkins University Press, 1982.

SADER, E. Mao Tsé-tung. Coleção Grandes Cientistas Sociais, v. 30, 1982.

SAFFIOTI, H. A questão da mulher na perspectiva socialista. Lutas sociais, n. 27, p. 82-100, 2011.

SCHIEBINGER, L. O feminismo mudou a ciência. Bauru: Edusc, 2001. 384 p.

"Getting more Women into Science: Knowledge Issues", Harvard Journal of Law \& Gender, v. 30, 2007.

. Creating Sustainable Science. Osiris, v. 12, n. 1, 1997.

Signs, v. 12, n. 2, 1987.

The History and Philosophy of Women in Science: A Review Essay.

The Mind Has No Sex? Women in the Origins of Modern Science.

Cambridge: Harvard University Press, 1989.

Nature's Body: Gender in the Making of Modern Science. Boston:

Beacon Press, 1993.

. O feminismo mudou a ciência? Campinas: EDUSC, 2001.

SCOTT, J. Gender and politics of history. New York: Columbia University Press, 1999. 
Gender: a useful category of historical analysis. The American Historical Review, v. 91, n. 5, 1986.

Gender: a useful category of historical analyses. Gender and the politics of history. New York: Columbia University Press, 1989.

SEGRÈ, E. A Mind Always in Motion: The Autobiography of Emilio Segrè. University of California Press, 1993. 332 p.

Wu, C. S. Entrevista I. [1974]. C.S. (Chien-Shiung) Wu Papers, 1945-1994 bulk 1960-1979. Columbia University Archives.

Entrevista II. [1963]. C.S. (Chien-Shiung) Wu Papers, 1945-1994 bulk 1960-1979. Columbia University Archives.

WU, C. S.; SHAKNOV, I. The angular correlation of scattered annihilation radiation. Physical Review, v. 77, n. 1, p. 136, 1950.

WU, C. S.; ALBERT, R. D. The Beta-Ray Spectra of $\mathrm{Cu}^{64}$. Physical Review, v. 75, p. 315, January 1949.

YANG, C. N. Selected papers, 1945-1980, with Commentary. World Scientific, 2005. 603 p.

. The law of parity conservation and other symmetry laws of physics. Nobel Lectures Physics: 1942-1962, 1964. 468 p.

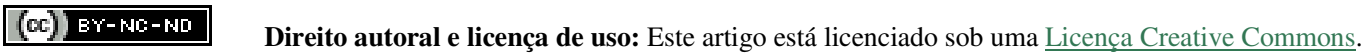

